Psychology of Language and Communication 2016, Vol. 20, No. 1

DE DE GRUYTER

宣

DOI: $10.1515 /$ plc-2016-0002

FRANCESCO ARCIDIACONO

University of Teacher Education BEJUNE

\title{
COLLABORATIVE RELATIONSHIPS AMONG COUPLES: FRAMES OF INTERACTION DURING EVERYDAY HOUSEHOLD ACTIVITIES
}

\begin{abstract}
The analysis of collaborative exchanges of couples during their household activities is at the core of this paper. Although the management of responsibilities around household tasks is a potential source of contention within the decision-making process about home activities, another complementary perspective considers practices of communication during household activities as ways to build or reinforce the family educational processes. Our goal is to capture these daily interactions as indicators of collaborative relationships among couples, exemplifying how communicative exchanges contribute to the creation of frames for family participation in routines. In the first part of the paper, a review of issues regarding the division of labor within the family setting will be introduced in order to examine how these aspects relate to the ongoing negotiation of responsibilities and expectations between women and men. Thereafter, the methodological design of the study will be presented, as well as the qualitative analysis of data based on the argumentative topic model. A discussion of participants' responsibilities in household tasks will be presented as indicators of their collaborative relationships during everyday activities. Lastly, implications for family studies will be highlighted in order to illustrate how family members ascribe meanings during routines.
\end{abstract}

Key words: family, argumentation, collaboration, couples, household activities

\section{Household work and parenting responsibilities}

Over the past few decades, several studies have investigated the complex modalities of couple interactions as they confront the everyday challenges of family life. In particular, research in the social sciences has demonstrated the impact of

Address for correspondence: Francesco Arcidiacono, Research Department, University of Teacher Education (HEP-BEJUNE), Chemin de la Ciblerie 45, 2503 Bienne, Switzerland. E-mail: francesco. arcidiacono@hep-bejune.ch 
couple representations related to the division of household work. Becker (1981) investigated household work in relation to gender stereotypes and to the balance of time and family activities. Schmidt (2000) observed the wide variation in how parents organize and manage everyday household tasks, and the impact of these issues on the quality of relationships and emotional landscape at home. More specific studies on marital interactions (Bradbury \& Karney, 1993; Bradbury, 1998; Pasch \& Bradbury, 1998; Klein et al., 2004; Johnson et al., 2005; Dunlap et al., 2010) have highlighted the effect of communication on couples' relationships when expressions of positive emotions, such as humor, interest, affection, and support, are relatively rare. These studies confirm that the consensual understanding of each partner's positions and duties at home are expected to promote efficient communicative interactions, whereas their inability to agree upon and enact a clear division of labor is expected to result in the continual re-negotiation of responsibilities. In turn, a lack of agreement is expected to engender discussion and contention as challenges involved in everyday family life, while argumentative exchanges also act as possible opportunities for negotiation (Arcidiacono, 2010; Bova \& Arcidiacono, 2013, 2014, 2015).

In the case of dual-earner couple studies in Europe and America (Christensen, 1988; Hochschild \& Machung, 1989; Coltrane, 2000; Emigh, 2000; Des RivièresPigeon, 2002; Klein et al., 2005; de Vaus, 2009; Arcidiacono et al., 2010), social challenges have been connected to how families attempt to balance work demands with household and parenting responsibilities. The wide variation in how working couples organize everyday household tasks and the manner in which they coordinate their actions around these tasks is a main factor affecting the quality of their lives. Hochschild (1997) found that dual-earner families define themselves in a time bind, whereby working adults increase the time they spend at work and consequently have little time left for leisure at home. As suggested by Goodnow (1989), household work is "more than a means of producing goods and services. It allows the work to be as well a vehicle for expressing love and affection, for claiming rights (the right to be looked after), and for negotiating equity" (pp. 39-40).

Apart from the direct impact of household work on family organization, the dimension of responsibility associated with the planning and management of chores at home remains a relevant issue. It is known that household tasks are distributed differently among different family members (Goodnow, 1988; Arcidiacono \& Pontecorvo, 2010a). While there are gender differences in the distribution of particular tasks, much of the variability is based on the status of the people involved and the perceived ownership of the task or orientation to work (Goodnow \& Delaney, 1989).

In our view, the study of family interactions during household tasks is a potential way to capture the value of these activities and the positions ${ }^{1}$ and respon-

\footnotetext{
${ }^{1}$ According to Arcidiacono and Pontecorvo (2010b, p. 450), "position is what is created in and through talk as participants take themselves up as people."
} 
sibilities of people within the family system. Through the analysis of exchanges during everyday activities at home, we also intend to provide access to indicators of collaborative relationships among partners when they are managing household demands. In particular, we will consider situations in which participants discursively align with or challenge each other's contributions (Arcidiacono, 2007) to be collaborative during their everyday activities at home.

\section{Aim and research questions}

Our goal is to capture everyday verbal exchanges during the home activities of couples in order to identify the indicators of their collaborative relationships. In particular, we intend to answer the following research questions:

a. How do couples discursively construct through different arguments about domestic work, individual and collaborative positions?

b. How do family members exhibit these collaborative relationships through indicators of participation during routines?

\section{Methodology}

\section{Participants and instruments}

This study is part of an international project jointly developed by three research centers (located in the United States, Sweden and Italy) and is based on an extensive ethnographic fieldwork (Arcidiacono \& Pontecorvo, 2004) in the domestic life of families. Specifically, this paper draws on data exclusively collected at the Italian Center on Everyday Lives of Families, which documents a week in the life of eight middle-class dual-income families in Rome. In order to be eligible to participate in the study, families were required to be homeowners with a monthly mortgage or with a monthly rent and to have at least two children living at home, with at least one between 8-12 years of age. Families were recruited through fliers in schools, and on occasion through teachers who were personally acquainted with the research team. After an initial meeting with the research team, both parents (and children over eight years of age) signed the consent forms of participation and received instructions concerning the timing and procedures of the study.

In this paper we refer to video-recorded interactions of Italian participant families documenting the activities of family members ${ }^{2}$ inside their homes over the course of a week, with an approximated 20-25 hours per family. The data were transcribed ${ }^{3}$ and used for a synoptic selection of similar instances of the

\footnotetext{
${ }^{2}$ In this paper we use the terms mother/father to refer to adult participants and child to refer to young people, even though they assume different roles during their interactions (not only as mother/father or child but also, respectively, as wife/husband, woman/man, and brother/sister). Participants' names are pseudonyms in order to insure anonymity.

${ }^{3}$ Cf. the appendix for transcription symbols (adapted from Jefferson, 2004).
} 
phenomenon under study. The two researchers who conducted the analysis using synoptic selection reached a significant level of inter-rate agreement demonstrated by a Cohen's kappa $=0.80(n=10$, value indicating the number of coding options that were taken into account for the phenomenon under study). We will present four excerpts of daily interactions among people during the planning and management of dinner preparation, activities that immediately follow dinner, as well as other daily duties such as making beds. These specific household tasks have been identified by researchers, in these data, as the major settings in which indicators of collaborative relationships emerge during exchanges among participants.

\section{Analytical approach}

Our analysis is based on an idiographic, local approach ${ }^{4}$ in order to examine participants' interactions during everyday life at home. Firstly, the study of verbal exchanges is assumed to be a privileged modality in investigating how people co-construct the meaning of their interactions. Relevant phenomena concerning the object of study were identified and organized as a collection of excerpts of similar instances (Arcidiacono et al., 2011). This procedure intended to capture the participants' activities during their spontaneous interactions. In other words, participants' accounts were positioned in the context of discourse production and addressed the concerns of people engaged in the interaction. Secondly, our analytical approach relies on the Argumentum Model of Topics (hereafter AMT), which aims to systematically reconstruct the inferential configuration of arguments during verbal exchanges, namely the structure of reasoning underlying the connection between a standpoint and the argument(s) in its support (Rigotti \& Greco Morasso, 2011). More specifically, AMT identifies the following elements: a topical component, which focuses on the inferential connection activated by the argument and corresponding to the abstract reasoning justifying the passage from premises (arguments) to the conclusion (standpoint); and an endoxical component, which consists of the implicit or explicit material premises shared by discussants which, combined with the topical component, ground the standpoint. According to AMT, the analysis of verbal exchanges is based on the following indicators: the maxim on which the argumentation is based; the endoxon, i.e. the premises shared by discussants; and the datum, i.e. the punctual information and facts regarding the specific situation at hand to which the argument is linked.

The two methods adopted for the analysis of couple verbal interactions have been integrated in their use: in fact, we consider the argumentative model to particularly fit our study because it describes how argumentative discourse would be structured when aimed at resolving differences of opinion. In our work, the model is assumed to be a guiding framework for the analysis, since it provides the criteria for the investigation of argumentative exchanges and for the identification

\footnotetext{
${ }^{4}$ For more details, cf. Salvatore \& Valsiner (2009); Arcidiacono (2015).
} 
of different components of the discourse. It is used to highlight points of contention as well as the explicit and implicit arguments advanced by family members. The application of this analytic method in the study of verbal interactions will reinforce the possibilities of understanding how couples discursively position themselves as collaborative partners in the management of some household activities, and how these interactions are exhibited through different arguments.

\section{Results}

Data are organized around sequences of interaction within specific situations, namely dinner preparation, its management and the practice of making beds, which we identified as three of the major household activities of the participant families. In the presentation of excerpts, the original Italian transcription of verbal interventions will follow the English translation ${ }^{5}$. AMT will be used to strengthen the discussion around each example and to summarize the arguments invoked by participants in their collaborative exchanges.

\section{Positioning as expert/authority}

The first excerpt deals with a collaborative activity in which one partner is perceived (and positioned) as an expert/authority in the particular task of cooking. The situation concerns dinner preparation during a weekday in the home of the RIPE family. The mother is baking a fish in the oven and the rest of the family is waiting for dinnertime in the living room. The selected sequence starts when the father enters the kitchen and asks the mother about the timer on the stove, in order to know when dinner will be served. An exchange between the mother and the father follows, involving - at a certain point - the child Leonardo.

Excerpt 1. RIPE family (Thursday evening). Participants: mother, father, child (Leonardo, 13 years old)

((the mother is in the kitchen and the father enters))

540. Father: has it gone off? ((the timer on ha suonato? ((il timer del forno))
the stove))

541. Mother: no. no.

542. $\quad(($ the timer on the stove went off $)$ ((il timer si spegne))

\footnotetext{
${ }^{5}$ Translation of utterances has been conducted not word-by-word, but to represent what the respondents were saying in their mother language.
} 
543. Father: now we check to see if it's adesso vediamo se é cotto. cooked.

((the fish is in the oven and the father ((il pesce nel forno e il padre is checking by looking at it quickly)) controlla guardando rapidamente))

${ }^{\circ}$ it isn't cooked ${ }^{\circ}$ ${ }^{\circ}$ non é cotto ${ }^{\circ}$

544. Mother: it isn't cooked? non é cotto?

545. Father: ( )

546. Mother: but it's possible that it'll be very ma é possibile che si secchi? dry?

547. Father: so this is the right way.

quindi va bene cosi.

548. Mother: I have to check, wait. devo controllare, aspetta.

$549 . \quad(6.0)$

((the mother opens the oven in order to check the fish))

((la madre apre il formo per controllare il pesce))

550. Father: you have to check devi controllare

551. Mother: no- no, I understand the consis- no- no, capisco la consistenza. tency.

it's cooked, but no. maybe a é cotto, ma no. forse un po' di little bit of

( ) the fish will be cooked inside ( ) il pesce sarà cotto dentro eh eh

((she is checking the fish by ((controlla il pesce inserendo la inserting a fork into the thickest area of the fish)) fork into the thickest area of the fish))

552. Father: yes. si.

((the child enters in the kitchen))

553. Child: how much more time?

quanto tempo ancora?

554. Father: we are waiting a few minutes dobbiamo aspettare qualche for the grill minuto per il grill

555. Child: have you added salt in the middle? hai aggiunto il sale in mezzo? 
556. Father: yes, mom added the salt!

557. Mother: mom added it.

558. Father: we have also added mushrooms

559. Child: on mine?

560. Father: on yours, too. si, mamma ha aggiunto il sale!

mamma l'ha aggiunto.

abbiamo aggiunto anche i funghi

sul mio?

sul tuo, anche.

Excerpt 1 is about a situation in which the partners take different positions during the dinner preparation. More specifically, the couple is discussing the fish baking in the oven and one partner assumes the role of expert/authority. The father, opening the oven door in order to check the fish, says in turn 543 'now we check to see if it's cooked.' By using the first person plural, he is framing the activity as collaborative (Oropeza-Escobar, 2011). As an effect of his action, he adds in a low voice but loud enough for the mother to hear that the fish 'isn't cooked.' The mother uses the father's formulation in turn 544 ('it isn't cooked?'), expressing her expectation that the fish should be done by now. This intervention opens the possibility to check whether they continue to bake the fish that might end up 'very dry' (turn 546). Using this moment to reclaim responsibility (the father was the first to check the status of the food in the oven, but now it has become a matter for both parents), the mother positions herself as an expert in turn 548 ('I have to check, wait'). She assumes the whole responsibility of the activity, relegating the father to a subordinate position. As a consequence, the father defers to the mother in turn 550 ('you have to check') and ratifies the fact that she should examine the fish.

While the interaction seems to proceed with a presumption of the mother's greater expertise, the accomplishment of this expertise is somehow shared. In turn 551, the mother announces the outcome of her investigation. Even though this finding contradicts the father's original findings (turn 543), it is done in a rather mitigated way (cf. the announcement 'it's cooked' into turn 551)'. In framing the activity as a collaborative interaction, the father manages to redress the balance of responsibility of the dinner preparation when Leonardo (coming in the kitchen) asks about the time until dinner (turn 553, 'how much more time?'). The autoselection of the father in turn 554 ('we are waiting a few minutes for the grill') is an opportunity to take a position similar to the mother in the eyes of the child. In fact, the plural pronoun 'we' is once again used as a way of including both parents and to indicate the collaborative aspect of the activity. This position is maintained until the end of the sequence and the parents align together when

\footnotetext{
${ }^{6}$ Cf. Pomerantz (1984) on preference for agreement.
} 
they answer the son's query about the salt (they both claim that the mother has added it and immediately the father adds that they also have added mushrooms, probably to agree with the son's preferences for food). In terms of the analytical structure of the arguments invoked by the couple, we can highlight different elements which contribute to the demonstration of how participants coordinate their verbal interventions. Firstly, the episode seems to speak to the prevention of argumentative potentialities in sequences ${ }^{7}$. Considering the first argument used by the father ('The timer on the stove went off but the fish is not cooked'), the finding that the fish is not cooked is treated as provisional rather than as definitive, as demonstrated by the mother's understanding in turn 544 ('it isn't cooked') which could prefigure disagreement. Following the father's inaudible response, in turn 546 the mother highlights the negative consequences of continuing to cook the fish if the father's finding turns out to be incorrect. The father's finding has implications for what happens next (e.g., to continue cooking or to stop); however, this is very different from advising the mother on what she should do and it is taken to demonstrate a need for further investigation.

Before showing AMT reconstruction, the issue, the two opposite standpoints and the argument in support of one of the opinions are stated below:

Issue $\rightarrow$ Can the father establish whether the fish is well cooked?

Standpoint $\rightarrow$ Mother: the fish should be cooked (according to the timer on the stove)

Argument $\rightarrow$ Father: the timer on the stove went off but the fish is not cooked

The AMT representation of these elements, inferred by the participants' interventions, is illustrated in Figure 1.

On the right side of the model, the inferential principle is the maxim on which the considered argument is based (If a situation admits alternative possibilities, then the decision by the person with the most experience must be accepted). The reasoning refers to the following inferential structure: The mother's expertise in cooking the fish is more adequate than the father's competence; therefore, the mother's decision must be accepted and the father can't establish by himself whether or not the fish is well cooked. At the same time, this kind of argument is sustained by an endoxical component. In fact, the first conclusion needs further justifications which are not inferential rules but factual statements that must be backed by contextual knowledge. The left side of the model is a representation of the participants' reasoning, developed in order to support the former one. This explains the fact that the first conclusion becomes a minor premise, crossing contextual and formal components of the structure represented by AMT. In

\footnotetext{
${ }_{7}$ Generally speaking, the different arguments used by participants can be viewed in terms of the constellations of features (Goodwin M. H., 2006) including various interactional structures (control, directives, accounts, etc.). For practical reasons, in AMT we propose one example based on a selected argument, although we are aware that this remains a (partial) choice.
} 
Figure 1. The inferential structure of the argument in excerpt 1

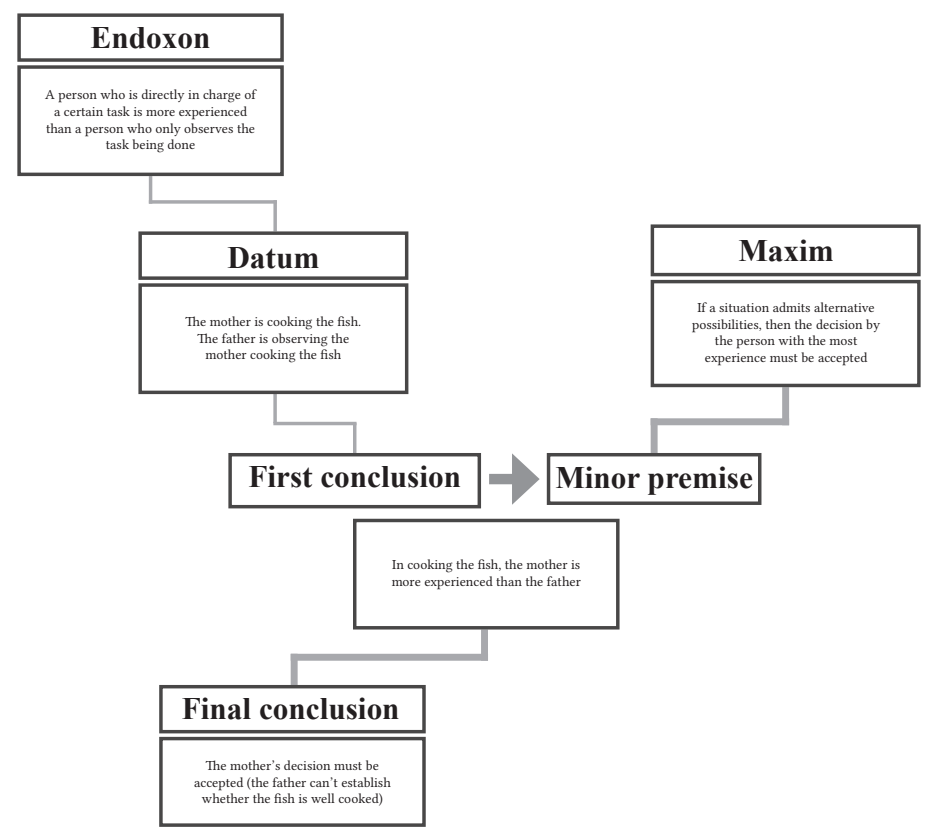

particular, the activity of cooking relates to the premise that the person who is directly in charge of the task is usually more experienced than the person who only participates in a marginal way (by observing).

\section{Coordinating activities within a large spatial configuration}

The second example occurs on the front end of a task in which collaboration is a possibility: partners try to coordinate together in organizing dinner and other activities. In fact, the mother is in charge of cooking, while the father moves between the kitchen and the living room, where the children are doing their homework.

At the beginning of excerpt 2, the father is alone in the kitchen and asks the children how they are managing their homework before dinnertime. In turn 105 he declares his intention to everyone ('I'll prepare the dinner') but, immediately after, the mother enters the kitchen. At this point, he partially modifies his previous proposal. In fact, he changes his status from the person in charge of cooking to the person available to assist the mother in preparing dinner (turn 107 'can I help you?'). In fact, the mother takes the position of being responsible for the activity. In turn 108 'no' refers to the father's offer of help although she is 
Excerpt 2. PICO family (Tuesday evening). Participants: mother, father, child (Serena, 10 years old)

((the father is in the kitchen while the mother is in the bathroom. Children are in the living room, just in front of the kitchen))

103. Father: how is the homework going come va con i compiti li, tutto there, everything all right? bene? ((ai bambini)) ((to children))

104. Child: I- (1.0) geography and science io- (1.0) geografia e scienze

105. Father: I'll prepare the dinner preparero' la cena

106. ((the mother is entering the kitchen))

107. Father: can I help you? ((to the mother)) posso aiutarti? ((alla madre))

108. Mother: no. ah: put the water to cook no. ah: metti l'acqua per cuocere la the pasta pasta

109. Father: the little one? quella piccola?

((referring to the pot)) ((riferendosi alla pentola $))$

((he holds up a pot)) ((prende una pentola $))$

110. Mother: ehm::: yes put in two ((pots)) ehm::: si metti in due ((pentole))

like this. ((pointing the presumed cosi. ((indicando il livello di acqua level of water in the pot)) presunto nella pentola))

we'll take less time to cook ci mettiamo meno tempo per cuocere

111. Father: then? what can I do? poi? che cosa posso fare?

112. Mother: nothing:: (1.0) I did not put the salt niente:: (1.0) non ho messo il sale ((in the pot)) but you (1.0) is not ((nella pentola)) ma tu (1.0) non é for you per te

113. Father: no:::::: not the salt, I'm scared no:::::: il sale no, ho paura

114. Mother: go and check the homework vai a controllare i compiti ((referring to the children in the ((riferendosi ai bambini nella living room)) sala))

otherwise:: this evening altrimenti:: stasera

115. Father: I'm going to check the homework vado a controllare i compiti otherwise we'll eat at midnight altrimenti mangeremo a mezzanotte

116. $\quad(($ he goes out from the kitchen $)) \quad$ ((esce dalla cucina $))$ 
proposing that he contributes to the cooking ('put the water to cook the pasta'). Interestingly, "put" is a bilateral imperative (Rossi, 2012) by which the requested action is integrated to an already established joint project (in terms of actions coherently articulated to achieve an interactive outcome, cf. Lerner, 1995) between the requester and recipient. A few turns later, the father once again offers his help (turn 111 'then? what can I do?') but the mother's answer does not allow further possibility to contribute, at least in the kitchen. She re-orients the father's position, inviting him to check the children's homework while she cooks (turn 114 'go and check the homework'). Her attention to the children that are studying in another room is a direct invitation to the father who, although trying to help the mother in preparing dinner, accepts the new task of monitoring the children's activity. He immediately goes to check the homework, assuming a double position acted by his moving back and forth between the two activity settings (the kitchen and the living room). Another viable interpretation is that the mother rejects the father's offer of help because the task requires only one person, although without visible elements of contention. However, in the present case we are not able to provide further details (e.g., gaze patterns, body orientation, and gestures) that could potentially assist in explaining the participants' positions. Excerpt 2 is particularly interesting because the participants show how dividing labor in order to achieve a common goal could be a routinized practice. Recently, a study conducted by Couper-Kuhlen and Etelämäki (2014) indicated that participants in everyday conversations use specific linguistic resources for this kind of practice, as bi-partite constructions that consist of requests to the other to carry out some action, and a self-commitment to carry out a complementary action. As in our case, proposals of labor division divide not only the tasks, but also the right to decide, responsibilities, and a way in which to transform asymmetric actions (such as offers and requests) into more symmetric ones.

As different interpretations are possible, in this case the identification of the elements for an AMT analysis is done as a post hoc exercise in filling the components of the model. We have selected the following elements:

Issue $\rightarrow$ Should the father cook?

Standpoint $\rightarrow$ The mother is in charge of cooking

Argument $\rightarrow$ Mother: the father can't do anything, but he can go to check children's homework

A representation of the elements inferred by the participants' interventions is provided in Figure 2.

Considering the inferential principle (the maxim) on which the argument is based (if there are different options, the decision by the most capable person must be accepted), we could consider the following structure of reasoning: The mother is the most capable person to cook; therefore, the mother's decision must be accepted and the father has to check on the children's homework instead of cooking. On the 
Figure 2: The inferential structure of the argument in excerpt 2

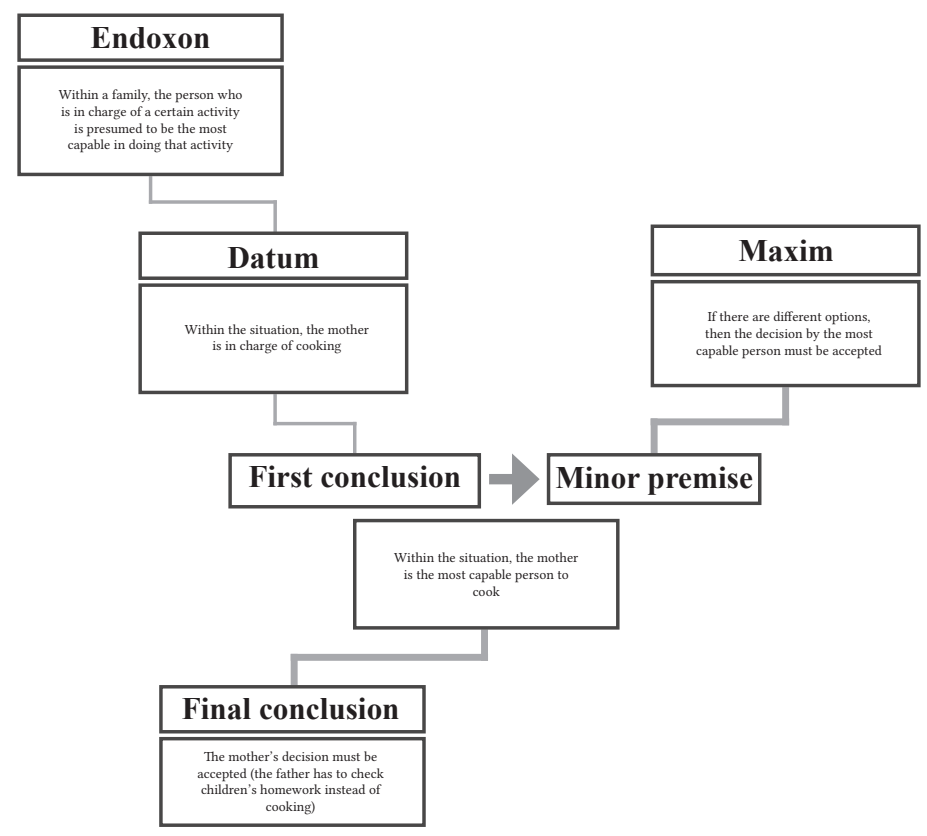

left side, the endoxical component sustaining the first conclusion is represented in order to indicate factual statements backed by contextual knowledge: the person who is in charge of the activity (within the specific situation, the mother is cooking) is presumed to be the most capable in executing that activity.

\section{Playful agreement in the 'here and now'}

In the management of household activities, there are situations in which the modalities of collaboration are established in the 'here and now' of precise activities, involving all family members. In the following excerpt, at the end of a dinner the PICO family is planning the next activities, including washing dishes. The situation is presented in a playful way and the household task becomes almost irrelevant.

At the end of the dinner, the father playfully and ironically aligns himself with the children to "face" the mother, asking what they have to do. His question in turn 340 ("okay mom what do we do?") places the mother in the role of the authority who determines what needs to be done and assigns tasks to the rest of the family. An interesting use of personal deixis (cf. Benveniste, 1966) is made here: from one side, the plural "we" might have an inclusive reading, as 
Excerpt 3. PICO family (Wednesday evening). Participants: mother, father, child 1 (Daniela, 12 years old), child 2 (Serena, 10 years old)

((family members are in the kitchen, still at the table after the dinner))

$\begin{array}{lll}\text { 340. Father: } & \text { okay mom what do we do? } & \text { va bene mamma che facciamo? } \\ & (\text { looking } \text { at the children })) & ((\text { guardando } \text { i bambini }))\end{array}$

341. Child 1: what does she do. che cosa fa.

342. Mother: what awaits me:: oh my god:: che mi aspetta:: oddio mio::

343. Father: the omelet dishes you are going i piatti con la frittata li lavi tu, to wash on your own, because perché poi-

later on-

344. Mother: practically all of them.

praticamente tutti.

345. Father: we only saved three plates- abbiamo salvato solo tre piattiokay let's help mom for a while va bene aiutiamo mamma un attimo

346. Mother: no=no no=no

347. Father: no? shall we go and play:: are you no? possiamo andare a giocare:: going to let us play mom? ci lasci andare a giocare mamma?

348. Mother: yes si

349. Father: well-done::!! bene:::!

350. Mother: you do it every evening anyway, tanto fate questo tutte le sere, it is not that:: non é che::

351. Father: Father: have you heard Tomas? hai sentito Tomas? ((il cane dei ((the neighbors' dog is barking)) vicini sta abbaiando)) anche Tomas too said go go:: have you Tomas ha detto vai vai:: hai heard Tomas: go go, Tomas agrees sentito Tomas: vai vai, Tomas (4.0) let's go to the little room é d'accordo (4.0) andiamo nella ((the father and the children leave cameretta ((il padre e le bambine the kitchen and go to the children's escono dalla cucina e vanno nella bedroom)) stanzetta))

a question involving all family members (what do we do now, all of us); from the other side, we can make the hypothesis that the father is establishing two sides (the mother versus the others, father and children together) by looking at 
the children while asking the mother about what he and the children have to do (excluding the mother from the "we" referred to the children and himself). This ongoing alliance seems confirmed by Daniela's intervention (turn 341, "what does she do"), which questions the father's perspective and reframes the situation. In fact, she is somehow enforcing the mother's matter: the stress on the pronominal switch denotes the mother as responsible for the impending household tasks. The mother takes up a humorous stance to the dinner clean-up work in her utterance "what awaits me oh my god." The vowel elongation and the intonational stress humorously and dramatically frame her task as monumental. Although the father downgrades his offer by suggesting that they can help (turn 345, "okay let's help mom for a while"), the mother refuses (turn 346, "no no") and he comically asks the mother's consent to go and play (turn 347, "no? Shall we go and play, are you going to let us play mom?'). In this way, the father once again attempts to place the mother in an authoritative role and, at the same time, he guarantees his own position on the children's side. After few seconds, in turn 350 ("you do it every evening") the mother aligns herself with the new structure of alliance: she ironically points out that it is a routine to be the one to clean up while the others play. At the end, the father personifies the neighbor's dog (turn 351, "Tomas too said go", "Tomas agrees") in order to reinforce his position on the children's side and to legitimize the choice to leave the kitchen and to go play. In demonstrating closeness to the children's needs, the father uses some epistemic and affective stances ("mom", "we can play?"), sustaining the mother's position as the person who knows how to manage after dinner activity better (specifically, washing dishes). This allows both the daughters and the father to leave the kitchen together.

In the identification of a key-element of excerpt 3 for the AMT, we selected the following argument used by the father: Let's go to the little room.

Issue $\rightarrow$ Can the father go play with the children?

Standpoint $\rightarrow$ The mother is able to manage the household task

Argument $\rightarrow$ Father: everybody agrees that it is not necessary to remain in the kitchen to help the mother to manage household tasks

In Figure 3 we represent the elements inferred by the participants' interventions.

Considering the inferential principle (the maxim) on which the argument is based (if a certain activity asks for certain necessary conditions, then all these conditions must be realized), we could consider the following structure of reasoning: The mother's capacity to manage household tasks is a necessary condition for the father to have the possibility of doing something else with the children; therefore, the father can go play with the children in the little room. On the left side of the figure, the endoxical component sustaining the first conclusion is represented in order to indicate factual statements backed by contextual knowledge. 
Figure 3: The inferential structure of the argument in excerpt 3

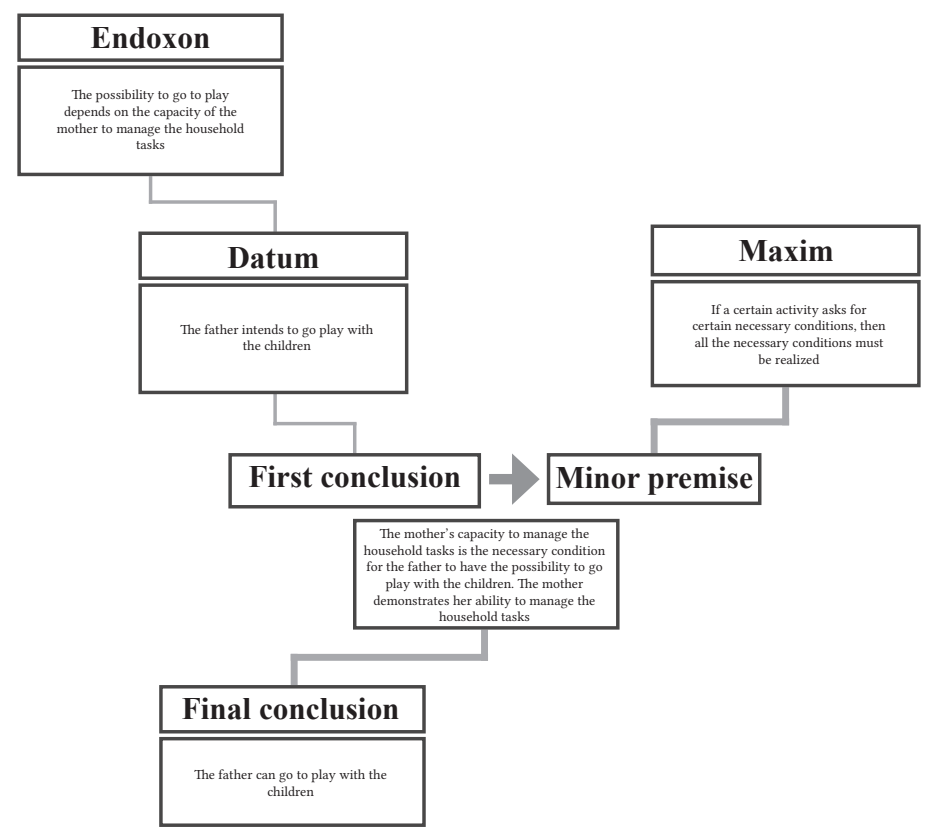

\section{Performing an activity by taking control}

We observed situations in which parents may pay a lot of attention to routine activities (such as making beds) by taking total control of the action. In the following excerpt, a father is performing this task with no collaboration from his daughter, who is sitting next to the bed. The father climbs upon the top bunk to put the child's stuffed animals away on the shelf above her bed. In talking to the researcher, he describes the operation in a humorous key, complaining about the number of stuffed animals the child currently sleeps with. He also adds that his life has become much more complicated since the child moved up to sleep on the top bunk because now the toys can no longer be left on the top bunk where she sleeps, as they once could when she slept on the bottom bunk.

The activity of making the bed that is described in the selected sequence is quite particular: instead of constructing the child as an agent who is perfectly capable of making her bed, the father walks into Elena's bedroom and begins working on the bed, leaving the child peripheral to the activity. The sequence starts with a comment initiated by the researcher, while the father climbs up the bottom bunk. The father describes the difficulties of the task, the sense of parental duty in accomplishing it (turn 9, 'we have to tidy up'), an accommodation 
Excerpt 4. GITI family (Tuesday morning). Participants: Father, child (Elena, 8 years old), researcher (Res)

((the father goes in the child's bedroom, where Elena is. He starts making the bunk bed. The mother and the other child are in the kitchen))

10. Res: Paolo ((the father)) but do youhave Paolo ((il padre $)$ ) ma ti tocca to do acrobatics every morning? fare le acrobazie ogni mattina? ((referring to the father's action ((riferendosi all'azione del padre of climbing upon the top bunk)) che sale sul letto di sopra))

11. Father: no, I have to say that before, when no, devo dire che prima, col fatto Elena slept there: (.) ((referring to che Elena dormiva li: (.) bottom bunk)) if she happened to ((riferendosi al letto di sotto)) make a mess like this we would se proprio faceva questi pasticcili leave it on the top bunk. now that lasciavamo sul letto di sopra. she sleeps up here, thoughadesso che dorme quassu', invece-

12. Res: I see h. h.

capisco h. h.

13. Father: it is necessary for us to tidy up. also because, instead of just sleeping with one stuffed animal, which would be- .h norma:1, ((he straightens up sheets and duvet)) > anyway< the- the quality of my life has gotten slightly worse since Elena started ci tocca mettere a posto. anche perché, anziché dormire con un solo pupazzo, cosa che sarebbe.h regola:re, ((tira su lenzuola e piumino)) $>$ comunque $<$ la- la qualità della mia vita da quando Elena dorme in questo letto è sleeping in this bed.

14. Res: ah yes. h. h.

ah si. h. h.

15. Father: yes because it was, definitely si perché era, decisamente più easier to make that other $\downarrow$ bed. semplice fare quell'altro \letto.

16. Res: mhm mhm. $\mathrm{mhm}$ mhm.

17. Child: well $\uparrow$ then $y-$ you are $<$ la:zy. $>=$ all $\uparrow$ ora $t-$ tu sei $<$ pi:gro. $>=$

18. Father: we'll put it like that. beh, mettiamola cosi.

to the child's habits (regarding stuffed animals in the bed), and, in general, the quality of his life (becoming worse since the child moved up to the top bunk). The sequence highlights how parental responsibility is taken for granted by this 
father and the task is framed as difficult. The parental burden for household chores is displayed in front of the child, who became part of the interaction that initially involved only the researcher. In fact, in turn 15 the father says that it was easier to make the other bed, and the child immediately replies "well, then you are lazy" (line 17). This comment made by Elena points to the ideology that it is a father's responsibility to make the bed and that, consequently, complaints about the burden are unacceptable. Another possible interpretation could be that the adult here is complaining about something to an outsider, in the presence of the child, whose "fault" it is that her father is having the trouble about which he is complaining. As this is an awkward situation for the child, one way to deal with it is to disown the fault. These elements are interesting in terms of ethnographic and discursive approaches (Zinken \& Borek, 2012) because participants' experiences and practices can be highlighted according to the perspective that the researcher is taking.

AMT is now employed to reconstruct the structure of the argument used by the father: The quality of my life has gotten slightly worse.

Issue $\rightarrow$ Is the father's quality of life getting worse because of differences in tiding up beds?

Standpoint $\rightarrow$ The child's choice to sleep with numerous stuffed animals increases the difficulty of tiding up beds, independently of the father's presumed lazy attitude

Argument $\rightarrow$ Father: tidying up the bed is a difficult activity

Figure 4 represents the elements inferred by the participants' interventions.

Considering the inferential principle (the maxim) on which the argument is based (the easier the activities are to be accomplished, the better the quality of life), we could consider the following structure of reasoning: Tidying up the bed is a difficult activity; therefore, the quality of the father's life is slightly worse. On the left side, the endoxical component sustaining the first conclusion is represented in order to indicate factual statements backed by contextual knowledge.

The excerpts presented above are some examples of collaborative modalities that we found among the observed couples. Participants choose and manage different forms of cooperation surrounding household tasks, in relation to the specific situations (in our case, dinner preparation, its management and the activities that follow, as well as the routine of making beds), to the value of the activity (such as doing something for the partner or for the children's benefit), and to their expertise. The inferential and endoxical structures of the arguments used by family members allow us the possibility of representing their ways of positioning themselves during interactions and creating frames within the family context. In particular, we could attempt to highlight the following four different outcomes in terms of the collaborative ways of activated shared processes within the observed family frameworks: 
Figure 4. The inferential structure of the argument in excerpt 4

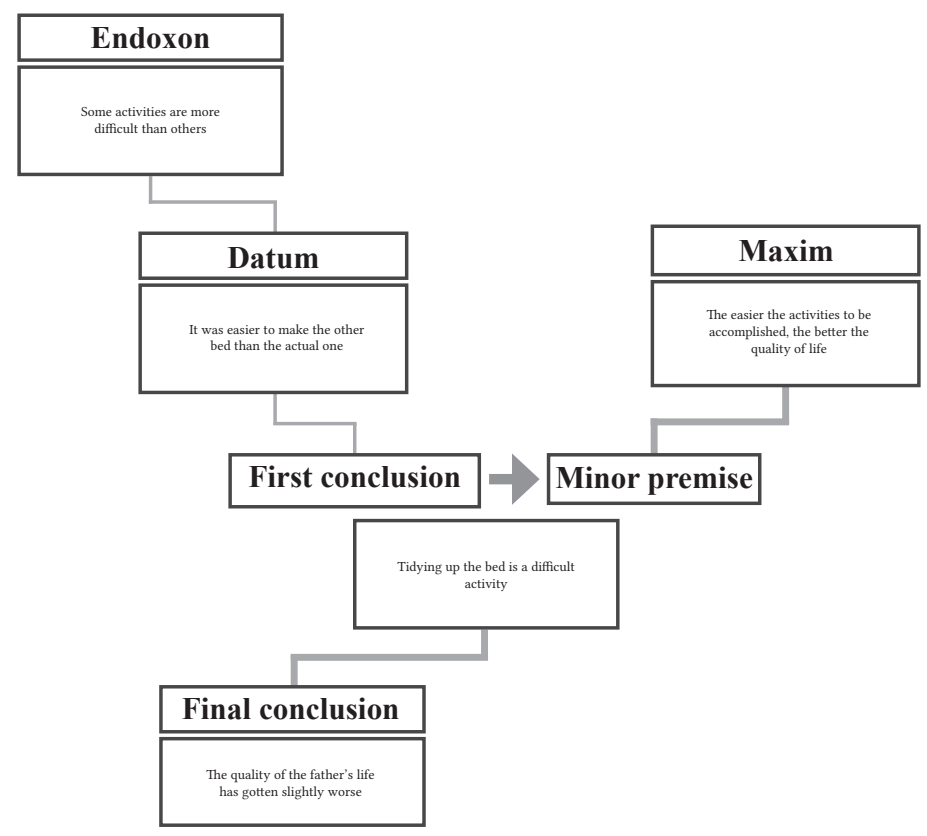

These aspects will be discussed in the following part of the paper in order to highlight different dimensions of collaboration that emerge during household activities.

\section{Discussion and conclusion}

A first point emerging from our investigation concerns the possibility of understanding how couples negotiate and enact verbal interactions for collaborating in household tasks. The excerpts presented above are examples of how the moment of dinner preparation/management and the organization of routines such as making beds could be spaces of collaborative relationships between partners and family members. At the same time, these are occasions that require continuous confrontation and dynamic positioning. These dynamic approaches enable us to examine specific thoughts, beliefs and attitudes that people make visible within family frameworks in a retrospective and prospective orientation of utterances and actions (Goodwin C., 2006). In fact, the capacity to collaborate becomes generative for each participant through verbal exchanges, in the sense that their original points of view are continuously changed during confrontation with a partner. In all of the excerpts couples were acting in order to accomplish 
Figure 5. Outcomes in terms of collaborative processes

\begin{tabular}{|l|l|l|}
\hline $\begin{array}{l}\text { Type of reasoning } \\
\text { connected to the } \\
\text { argument advanced by } \\
\text { a member of the couple }\end{array}$ & $\begin{array}{l}\text { Modality used to engage } \\
\text { other family members }\end{array}$ & $\begin{array}{l}\text { Example of observed } \\
\text { situation }\end{array}$ \\
\hline $\begin{array}{l}\text { When a situation admits } \\
\text { alternative possibilities, } \\
\text { the expertise of a family } \\
\text { member can be a reasonable } \\
\text { criterion to establish the } \\
\text { choice to be done }\end{array}$ & $\begin{array}{l}\text { To help the partner } \\
\text { is cooked or not }\end{array}$ & $\begin{array}{l}\text { The mother takes the posi- } \\
\text { tion of expert within the } \\
\text { fish cooking activity: } \\
\text { "I have to check, wait" }\end{array}$ \\
\hline $\begin{array}{l}\text { When different options } \\
\text { are possible, the directives } \\
\text { of the person positioned } \\
\text { as responsible can be the } \\
\text { efficient way to orient the } \\
\text { other participants' } \\
\text { activities }\end{array}$ & $\begin{array}{l}\text { To direct the partner's at- } \\
\text { tention to other relevant } \\
\text { tivities }\end{array}$ & $\begin{array}{l}\text { The mother designates the } \\
\text { activity for the partner: } \\
\text { "go current ac- } \\
\text { ho and check the }\end{array}$ \\
\hline $\begin{array}{l}\text { When different activities } \\
\text { are proposed at the same } \\
\text { time, the conditions of } \\
\text { realization have to be } \\
\text { negotiated and agreed } \\
\text { among participants }\end{array}$ & $\begin{array}{l}\text { To ask open questions to } \\
\text { encourage shared participa- } \\
\text { tion in the family activities } \\
\text { To model how to appro- } \\
\text { priately deal with different } \\
\text { proposed activities }\end{array}$ & $\begin{array}{l}\text { The father and children } \\
\text { negotiate how to employ } \\
\text { "heir time with the mother: } \\
\text { "are you going to let us play } \\
\text { mom?" }\end{array}$ \\
\hline $\begin{array}{l}\text { When accomplishing some } \\
\text { activities, it is possible to } \\
\text { that affect the quality of } \\
\text { family members' lives }\end{array}$ & $\begin{array}{l}\text { To elaborate on exhibit } \\
\text { content by sharing past } \\
\text { experiences and feelings } \\
\text { which can help the other to } \\
\text { construct meanings }\end{array}$ & $\begin{array}{l}\text { The father expresses his } \\
\text { feeling in performing a } \\
\text { routine activity: "I have to } \\
\text { say that..." }\end{array}$ \\
\hline
\end{tabular}

household work, but always with a reference to other family members (the children) involved in their exchanges. In the first excerpt, the couple was acting as a unit, sharing the responsibility for preparing the fish in front of the child entering the kitchen. Excerpt 2 was an example of how, through the re-orientation of tasks, parents showed their organizational capacity and coordination in managing multiple activities (cooking and checking the homework). Interestingly, the near-repetitions in excerpts 1 and 2 ('you have to check', 'I am going to check') 
play a conversation role: in fact, in our cases repetitions do more than repeat what the earlier turn said and contribute to the continuity of conversation (Wong, 2000; Sidnell, 2010). The third excerpt concerned playful ways of dividing work and deciding about family activities, and the last excerpt underlined how ongoing actions can be used to express value connected to personal and family lives. Based on logical arguments, the participants showed the relevance of different elements that could contribute to engaging other family members in the activity at stake. In fact, we observed that when a situation admits alternative possibilities and options, the expertise of a family member is considered as a criterion for a choice, and directives serve to orient the other's activities. On the other hand, when different activities are proposed at the same time, a negotiation is requested in order to ensure the quality of family members' lives.

Another crucial element to be considered is the fact that the above-mentioned aspects play a fundamental role in creating the conditions most likely to promote collaborative engagement in couples and to define participation structures within family frameworks. As men and women monitor the challenges involved in achieving their goals (such as a strong division of labor or the overlap of tasks, a centralized or distributed control, etc.), these dimensions are descriptive rather than prescriptive. This could be in order to orient them towards some shared and contingent outcome. The management of household tasks is assumed to be a joint activity requiring mutual negotiation, recognition of expertise, and the evaluation of the pertinence of contextual elements during the carrying out of duties. In such a case, expertise in dinner preparation or making beds might be viewed as an ability to identify dimensions along which some reorientation could be done and to evaluate the effects of different choices and the margin of freedom they require. The exhibition of these (and other) dimensions through verbal exchanges is a fruitful way participants use to account for their collaborative relationships during the organization and management of household tasks. In fact, people create discursive positions through their exchanges (Hollway, 1984), which serve as helpful toolboxes to understand the ways they ascribe meaning to what they do. Collaborating through exchanges in this sense is a joint effort (Riedinger, 2012) in which knowledge is distributed among the family. The activation of knowledge structures is thus at the same time the result of the social relational context and a component of the individual discursive mind (Stemplewska-Zakowicz et al., 2014).

In comparison to other related studies, this paper suggests that the management of household activities has educational implications that encompass the context and the circumstances within which people strive to nurture themselves and their family. This point is relevant in terms of the culturally perceived gender positions of certain activities. For example, women are often considered decisive in some duties, such as dinner preparation. This common sense perception does not appear as an invariable condition in our sample: we found both partners col- 
laboratively engaged, as a sign of parental complex and multi-faceted functions. We are aware that more specific investigations of the cultural and educational implications of these dimensions are needed in order to illuminate new possible directions of positioning within family interactions. This will also enable us to highlight the effects of engaging in argumentation around everyday activities that have strong educational values (Arcidiacono et al., 2009; Pontecorvo \& Arcidiacono, 2014), offering opportunities to enhance decentration and to contribute to the shaping of communicative practices, fostering a critical attitude in adults and children during family interactions.

Finally, we are aware that the specific models of analysis we used contributed to the description of how argumentative discourse would be structured when aimed at resolving differences of opinions. However, we recognize that the present study has certain methodological limitations, notably regarding the generalization of the results considering the specificity of the considered settings. Further research, hopefully inspired by the outcomes of the present study, will contribute to a better understanding of the interplay between household labor, collaboration and argumentative exchanges within different activities and contexts.

\section{Acknowledgments}

We are grateful to the A. P. Sloan Foundation (New York, USA) for supporting this research, as part of the Program on Dual-Career Working Middle Class Families, and to our colleagues for discussing data and methodological approaches with us. We are also grateful to the participant families for opening their homes to us.

\section{References}

Arcidiacono, F. (2007). Studying the practice of cooperation and collaboration within an international research project on the everyday lives of families. Integrative Psychological \& Behavioral Science, 41 (2), 139-153.

Arcidiacono, F. (2010). The ethnographic observation of the everyday life in Italy: Collaborative interactions among working couples. In C.L. Goossens (Ed.), Family Life: Roles, Bonds, and Impact (pp. 99-118). New York, NY: Nova Science Publishers.

Arcidiacono, F. (2015). Argumentation and reflexivity. In G. Marsico, R. Andrisano-Ruggieri, \& S. Salvatore (Eds.), Reflexivity and Psychology (pp. 196-193). Charlotte, NC: Information Age Publishing.

Arcidiacono, F., Baucal, A., \& Budjevac, N. (2011). Doing qualitative research: The analysis of talk-in-interaction. In A. Baucal, F. Arcidiacono, \& N. Budjevac (Eds.), Studying interaction in different contexts: A qualitative view (pp. 17-45). Belgrade: Institute of Psychology. 
Arcidiacono, F., Klein, W., Izquierdo, C., \& Bradbury, T.N. (2010). Modalità interattive nella divisione del lavoro domestico: uno studio etnografico su famiglie italiane e statunitensi [Interactional modalities within the division of household labor: An ethnographic study among Italian and US families]. Rivista di Psicolinguistica Applicata, 10 (1-2), 85-105.

Arcidiacono, F. \& Pontecorvo, C. (2004). Più metodi per la pluridimensionalità della vita familiare [Diverse methods for a multidimensional study of family life]. Ricerche di Psicologia, 27 (3), 103-118.

Arcidiacono, F. \& Pontecorvo, C. (2010a). Where and how family members spend time at home? A quantitative analysis of the observational tracking on the everyday lives of Italian families. International fournal of Multiple Research Approaches, 4 (2), 113-129.

Arcidiacono, F. \& Pontecorvo, C. (2010b). The discursive construction of the fathers' positioning within family participation frameworks. European fournal of Psychology of Education, 25 (4), 449-472.

Arcidiacono, F., Pontecorvo, C., \& Greco Morasso, S. (2009). Family conversations: The relevance of context in evaluating argumentation. Studies in Communication Sciences, 9 (2), 79-92.

Becker, G.S. (1981). A Treatise on the Family. Cambridge: Harvard University Press.

Benveniste, E. (1966). Problèmes de linguistique générale [Problems of general linguistics]. Paris: Gallimard.

Bova, A. \& Arcidiacono, F. (2013). Invoking the authority of feelings as a strategic maneuver in family mealtime conversations. Fournal of Community \& Applied Social Psychology, 23 (3), 206-224.

Bova, A. \& Arcidiacono, F. (2014). "You must eat the salad because it is nutritious". Argumentative strategies adopted by parents and children in food-related discussions at mealtimes. Appetite, 73 (1), 81-94.

Bova, A. \& Arcidiacono, F. (2015). Beyond conflicts. Origin and types of issues leading to argumentative discussions during family mealtimes. Fournal of Language Aggression and Conflict, 3 (2), 263-288.

Bradbury, T.N. (Ed.) (1998). The Developmental Course of Marital Dysfunction. New York, NY: Cambridge University Press.

Bradbury, T.N. \& Karney, B.R. (1993). Longitudinal study of marital interaction and dysfunction: Review and analysis. Clinical Psychology Review, 13 (1), 15-27.

Christensen, K. (1988). Women and Home-Based Work: The Unspoken Contract. New York, NY: Holt.

Coltrane, S. (2000). Research on household labor: Modeling and measuring the social embeddedness of routine family work. fournal of Marriage and Family, 62 (4), 1208-1233.

Couper-Kuhlen, E. \& Etelämäki, M. (2014). On divisions of labor in request and offer environments. In P. Drew \& E. Couper-Kuhlen (Eds.), Requesting in Social Interaction (pp. 115-144). Amsterdam: Benjamins. 
Des Rivières-Pigeon, C. (2002). Division of domestic work and psychological distress 1 year after childbirth: A comparison between France, Quebec and Italy. Fournal of Community \& Applied Social Psychology, 12 (6), 397-409.

de Vaus, D. (Ed.) (2009). Family-work balance. Special issue. Journal of Family Studies, 15 (2), 118-187.

Dunlap, E., Golub, A., \& Benoit, E. (2010). The invisible partners: Cohabiting males as 'caring daddies' in inner-city 'mother-only' households. In C.L. Goossens (Ed.), Family Life: Roles, Bonds, and Impact (pp. 33-54). New York, NY: Nova Science Publishers.

Emigh, R.J. (2000). The gender division of labour: The case of Tuscan smallholders. Continuity and Change, 15 (1), 117-137.

Goodnow, J.J. (1988). Children's household work: Its nature and functions. Psychological Bulletin, 103 (1), 5-26.

Goodnow, J.J. (1989). Work in households: An overview and three studies. In D. Ironmonger (Ed.), Households Work (pp. 38-58). Sydney: Allen \& Unwin.

Goodnow, J.J. \& Delaney, S. (1989). Children's household work: Task differences, styles of assignment, and links to family relationships. Fournal of Applied Developmental Psychology, 10 (2), 209-225.

Goodwin, C. (2006). Retrospective and prospective orientation in the construction of argumentative moves. Text \& Talk, 26 (4-5), 443-461.

Goodwin, M.H. (2006). Participation, affect, and trajectory in family directive/ response sequences. Text \& Talk, 26 (4-5), 515-543.

Hochschild, A. (1997). Work Becomes Home and Home Becomes Work. New York, NY: Metropolitan Books.

Hochschild, A. \& Machung, A. (1989). The Second Shift: Working Parents and the Revolution at Home. New York, NY: Viking.

Hollway, W. (1984). Gender difference and the production of subjectivity. In J. Henriques, W. Hollway, C. Urwin, L. Venn, \& V. Walkerdine (Eds.), Changing the subject: Psychology, social regulation and subjectivity (pp. 227-263). London: Methuen.

Jefferson, G. (2004). Glossary of transcript symbols with an introduction. In G.H. Lerner (Ed.), Conversation Analysis: Studies from the first generation (pp. 13-31). Philadelphia, PA: Benjamins.

Johnson, M.D., Cohan, C.L., Davila, J., Lawrence, E., Rogge, R. D., Karney, B.R., Sullivan, K.T., \& Bradbury, T.N. (2005). Problem-solving skills and affective expressions as predictors of change in marital satisfaction. Fournal of Consulting and Clinical Psychology, 73 (1), 15-27.

Klein, W., Izquierdo, C., \& Bradbury, T.N. (2004). Working relationships: Communicative patterns and strategies among couples in everyday life (Working Paper n. 28). Los Angeles, CA: UCLA Center on Everyday Lives of Families.

Klein, W., Izquierdo, C., Bradbury, T.N., \& Arcidiacono, F. (2005). Collaboration and conflict: Insights into the division of household labor among working couples in the United States and Italy (Working Paper n. 36). Los Angeles, CA: UCLA Center on Everyday Lives of Families. 
Lerner, G.H. (1995). Turn design and the organization of participation in instructional activities. Discourse Processes, 19 (1), 111-131.

Oropeza-Escobar, M. (2011). Framing and collaboration in storytelling events: Forgetfulness, reflexivity and word search. Pragmatics, 21 (2), 213-230.

Pasch, L.A. \& Bradbury, T.N. (1998). Social support, conflict, and the development of marital dysfunction. Fournal of Consulting and Clinical Psychology, $66(2), 219-230$.

Pomerantz, A. (1984). Agreeing and disagreeing with assessments: Some features of preferred/dispreferred turn shapes. In M.J. Atkinson \& J. Heritage (Eds.), Structures of Social Action: Studies in Conversational Analysis (pp. 57-101). Cambridge: Cambridge University Press.

Pontecorvo, C. \& Arcidiacono, F. (2014). Social interactions in families and schools as contexts for the development of spaces of thinking. In T. Zittoun \& A. Iannaccone (Eds.), Activity of Thinking in Social Spaces (pp. 83-97). New York, NY: Nova Science Publishers.

Riedinger, K. (2012). Family connections: Family conversations in informal learning environments. Childhood Education, 88 (2), 125-127.

Rigotti, E. \& Greco Morasso, S. (2011). Comparing the Argumentum Model of Topics to other contemporary approaches to argument schemes: The procedural and material components. Argumentation, 24 (4), 489-512.

Rossi, G. (2012). Bilateral and unilateral requests: The use of imperatives and Mi X? interrogatives in Italian. Discourse Processes, 49 (9), 426-458.

Salvatore, S. \& Valsiner, J. (2009). Idiographic Science on its Way: Towards Making Sense of Psychology. In S. Salvatore, J. Valsiner, S. Strout, \& J. Clegg (Eds.), Yearbook of Idiographic Science. Volume 2 (pp. 9-19). Rome: Firera \& Liuzzo Publishing.

Schmidt, J. A. (2000). Daily Stressors in Families (Working Paper). Chicago, IL: Sloan Foundation.

Sidnell, J. (2010). Conversation Analysis: An Introduction. Chichester: WileyBlackwell.

Stemplewska-Zakowicz, K., Zalewski, B., Suszek, H., Kobylinska, D., \& Szymczyk, B. (2014). The discursive mind model. Psychology of Language and Communication, 18 (1), 1-21.

Wong, J. (2000). Repetition in conversation: A look at "first and second sayings". Research on Language and Social Interaction, 33 (4), 407-424.

Zinken, J. \& Borek, A. (2012). Working side by side? Interaction and interview data in research on household conflicts. Qualitative Research in Psychology, 9 (2), 99-113. 


\section{Appendix}

\section{Transcription symbols used in the excerpts}

. falling intonation

, continuing intonation

- $\quad$ abrupt cut-off

- quiet speech

( ) non-transcribing segment of talk

.h h. inhalation / aspiration
? rising intonation

! exclaiming intonation

: $\quad$ prolonging of sounds

(2.0) pause (seconds)

(.) micro-pause (less than 0.2) vocalic emphasis

(( )) segments added by the transcriber in order to clarify some elements of the situation

$><$ portions of an utterance delivered at a pace noticeably quicker than surrounding talk

$<$ portions of an utterance delivered at a pace noticeably slower than surrounding talk

$\uparrow \downarrow$ pitch resets; marked rising and falling shift in intonation

$=\quad$ latching of contiguous utterances, with no interval or overlap 